\title{
Biodegradación de los compuestos fenólicos presentes en el alpechín
}

\author{
Por R. Maestro Durán (1), R. Borja Padilla (1), A. Martín Martín (2), J. A. Fiestas Ros de Ursinos (1) \\ y J. Alba Mendoza (1). \\ (1) Instituto de la Grasa y sus Derivados (C.S.I.C.). Avda. Padre García Tejero n 4. 41012 - SEVILLA \\ (2) Departamento de Ingeniería Química. Facultad de Ciencias. Universidad de Córdoba. Avda. S. Alberto \\ Magno s/n. 14004 - CORDOBA.
}

\section{RESUMEN}

Biodegradación de los compuestos fenólicos presentes en el alpechin.

Las aguas residuales de la obtención del aceite de oliva - alpechines son responsables de la mayor contaminación medioambiental de Andalucía por su elevada carga de materia orgánica. Su depuración por biometanización es difícil debido a la actividad antimicrobiana de los compuestos fenólicos. Este tipo de sustancias puede eliminarse en gran parte tratando previamente el alpechín por vía aerobia con microorganismos específicos, después de lo cual la depuración anaerobia tiene lugar sin inhibiciones, siendo la constante de velocidad cinco veces superior a la de antes del pretratamiento.

En este trabajo se hace un estudio cualitativo de los fenoles por cromatografía en capa fina y cuantitativo de los fenoles totales, orto- y meta-difenoles, así como de la Demanda Química de Oxígeno del alpechín antes del tratamiento, después del pretratamiento y después de la biometanización.

Se ha comprobado también la ausencia de leucoantocianinas que pudieran dar origen a fenoles polimerizados.

PALABRAS-CLAVE: Alpechín - Compuestos fenólicos Depuración anaerobia - Pretratamiento aerobio.

\section{SUMMARY}

Biodegradation of phenolic compounds present in oil-mill wastewater.

Oil-mill wastewater is the main responsible of the pollution in Andalusian due to high content of organic substances. Its depuration by methanization is difficult because of the antimicrobial activity of phenolic derivatives. These compounds can be drastically reduced by a previous aerobic treatment of the oilmill wastewater with specific microorganisms. After this pretreatment, anaerobic depuration takes place without inhibition, the velocity of the reaction being 5 times higher than before the pretreatment.

In this paper a qualitative study of the phenols present in oil-mill wastewater by thin layer chromatography has been done. Beside that, quantitative determination of total phenols, ortoand meta-diphenols as well as Chemical Oxigen Demand (COD) before the treatment, after the pretreatment and after biomethanization have been carried out.

Finally, leucoanthocyanins that could originate polymerized phenols have not been found.

KEY-WORDS: Aerobic pretreatment - Anaerobic depuration - Oil-mill wastewater - Phenolic compounds.

\section{INTRODUCCION.}

La influencia de los fenoles y de los taninos (fenoles polimerizados) en la depuración de aguas residuales, tanto por métodos aerobios como anaerobios, es muy importante, debido a la actividad antimicrobiana de este tipo de compuestos. Se ha estudiado esta toxicidad para las bacterias metanogénicas en la depuración anaerobia de las aguas residuales de la industria del almidón a partir de patatas, donde son muy abundantes dos compuestos fenólicos, la tirosina y la hidroxitirosina (1), en las aguas residuales de la fabricación de coque, en las que hay altas concentraciones de fenol, meta- y para-cresol (2) y en las industrias papeleras que, entre otras sustancias altamente contaminantes, tienen dos de naturaleza fenólica, el guayacol y el eugenol (3).

La misión principal de los compuestos fenólicos en las plantas es inhibir a los microorganismos patógenos; no es de extrañar, por lo tanto, que sean tóxicas, por lo menos a concentraciones elevadas, para las bacterias que realizan la depuración (4), (5), (6), (7).

El efecto inhibidor sobre las bacterias metanogénicas depende del sustrato, del tipo de bacterias y de otros factores, como el pH del medio. En general, es mayor la toxicidad cuando este es ácido, como es el caso del alpechín.

Los fenoles existentes en el alpechín proceden de los glucósidos fenólicos de la pulpa y de la semilla de la aceituna. En el proceso de obtención del aceite, 
principalmente durante la molienda y el batido, estos glucósidos sufren hidrólisis de carácter químico, debida a la acidez y enzimático, por los enzimas hidrolíticos que quedan en contacto íntimo con sus sustratos; análogamente, la polifenoloxidasa, muy abundante en la pulpa, oxida y polimeriza parte de los polifenoles presentes especialmente los ortodifenoles.

En trabajos anteriores (8), (9) estudiamos los fenoles existentes en la pulpa de aceituna y en el alpechín, comprobando que los polifenoles, componentes mayoritarios de la pulpa, descienden considerablemente en el alpechín.

En el presente trabajo hemos procedido a estudiar, tanto cualitativa como cuantitativamente, los fenoles presentes en alpechines frescos y después de depurar estos por métodos aerobio y anaerobio (10).

Cuantitativamente hemos medido en extractos de alpechín con acetato de etilo los polifenoles totales, por valoración con el reactivo de Folin, los orto-difenoles por formación de quelato con molibdato sódico (reactivo de Arnow), y de meta-difenoles por reacción con vainillina-ácido sulfúrico. También hemos investigado la presencia de leucocianidinas, que resultó negativa (11).

Cualitativamente hemos estudiado los extractos de alpechín por cromatografía en capa fina de celulosa.

Paralelamente se ha determinado la Demanda Química de Oxígeno del alpechín en las distintas fases de su depuración.

\section{PARTE EXPERIMENTAL.}

\subsection{Extracción de los polifenoles del alpechín.}

Muestras de $20 \mathrm{ml}$ de alpechín se extraen con tres porciones de $20 \mathrm{ml}$ de acetato de etilo. Las fracciones reunidas se secan con sulfato sódico anhidro y se concentran a sequedad en el rotavapor. El residuo se disuelve en la menor cantidad posible de metanol (aproximadamente $1 \mathrm{ml}$ ). Esta solución se emplea para el estudio cualitativo de los polifenoles. Para el estudio cuantitativo se lleva con agua a un volumen conocido y de esta solución se toman partes alícuotas para determinar los fenoles totales y los distintos grupos de orto-, meta-difenoles y leucoantocianinas.

\subsection{Determinación de los polifenoles totales.}

En un matraz aforado de $50 \mathrm{ml}$ se agregan $35 \mathrm{ml}$ de agua destilada, $5 \mathrm{ml}$ de la solución acuosa de polifenoles y $2,5 \mathrm{ml}$ de reactivo de Folin-Denis (mezcla de ácidos fosfomolíbdico y fosfowolfrámico). Se agita para homogeneizar y después de 3 minutos, se añaden $5 \mathrm{ml}$ de una solución acuosa de carbonato sódico al
$20 \%$. Se lleva el volumen a $50 \mathrm{ml}$ con agua destilada, se mezcla todo bien y después de 1 hora de reposo se mide la absorción a $725 \mathrm{~nm}$ en cubeta de $1 \mathrm{~cm}$. Como blanco se utiliza una solución preparada igual pero sin añadir los polifenoles. Si la solución a medir está turbia o tiene algún precipitado, hay que filtrarla previamente. Es muy importante que la concentración de metanol en la solución que se mide no exceda del $5 \%$. Los resultados se expresan en ácido cafeico por diversas razones: es uno de los fenoles más abundantes en el alpechín, es fácil de adquirir en estado puro $y$, tanto por su carácter de orto-difenol como por su peso molecular representa un término medio entre los fenoles del alpechín, más adecuado que otros patrones que podrían usarse igualmente con este fin.

\subsection{Determinación de orto-difenoles.}

Este tipo de compuestos forma con facilidad quelatos con diversos metales, como el molibdeno, con el consiguiente cambio en el espectro de absorción, que sirve como base para la determinación de estos orto-difenoles.

La técnica seguida es la siguiente: $10 \mathrm{ml}$ de la solución se tratan con $2 \mathrm{ml}$ de una solución al $5 \%$ de molibdato sódico en etanol del $50 \%$. Otros $10 \mathrm{ml}$ se tratan con $2 \mathrm{ml}$ de etanol al $50 \%$ y esta solución es la que se toma como blanco. A los 15 minutos se mide la absorción a $370 \mathrm{~nm}$ de la solución tratada con molibdato frente a la del blanco. La concentración de orto-difenoles se expresa en ácido cafeico mediante la correspondiente curva patrón.

\subsection{Determinación de meta-difenoles.}

Se realiza por reacción con vainillina en medio ácido. En estas condiciones, los compuestos que tienen un núcleo de resorcina o floroglucina desactivado forman un colorante rojo, que se puede determinar colorimétricamente. La técnica seguida ha sido la siguiente: Se toman 2 muestras de $2 \mathrm{ml}$ de la solución problema (con menos de $0,1 \mathrm{ml}$ de metanol), que se colocan en sendos matraces cónicos de $25 \mathrm{ml}$ (A y B). Desde una bureta se añaden $4 \mathrm{ml}$ de reactivo (preparado recientemente disolviendo $1 \mathrm{~g}$ de vainillina en $100 \mathrm{ml}$ de ácido sulfúrico del $70 \%$ ) en el matraz A y $4 \mathrm{ml}$ de ácido sulfúrico del $70 \%$ en el matraz $\mathrm{B}$. Los matraces se agitan bien en agua fria y se dejan reposar 15 minutos a la temperatura ambiente. A continuación se miden las absorciones a $500 \mathrm{~nm}$ y en cubeta de $1 \mathrm{~cm}$ de las soluciones de los dos matraces y la de otro, $\mathrm{C}$, previamente preparado como blanco (4 $\mathrm{ml}$ de reactivo y $2 \mathrm{ml}$ de agua) frente a la de un cuarto matraz, D, con ácido sulfúrico al $47 \%(4 \mathrm{ml}$ de ácido sulfúrico del $70 \%$ y $2 \mathrm{ml}$ de agua). La absorción debida a los meta-difenoles se obtiene 
restando de la lectura de $A$ la suma de las lecturas $B$ y $C: E=A-(B+C)$. Los resultados se expresan en catequina o resorcina, de acuerdo con la adecuada curva patròn.

\subsection{Determinaciòn de leucocianinas.}

El mètodo se basa en la transformación de leucocianinas en antocianinas coloreadas por calentamiento con ácidos.

Se coloca $1 \mathrm{ml}$ de la solución a investigar en un tubo de ensayo con tapón esmerilado. Se añaden 10 $\mathrm{ml}$ de reactivo (obtenido diluyendo $25 \mathrm{ml}$ de ácido clorhídrico concentrado con n-butanol hasta $500 \mathrm{ml}$ ), se homogeneiza y se coloca durante 3 minutos en un termostato a $97 \pm 1^{\circ} \mathrm{C}$. A continuación se tapa el tubo y se mantiene esa temperatura durante 40 minutos. Se destapa ahora, se enfría en agua corriente y se mide la absorción en cubeta de $1 \mathrm{~cm}$ a $550 \mathrm{~nm}$, frente a un tubo sometido al mismo tratamiento, pero sin calentar. Los resultados pueden expresarse como cloruro de ciadina.

\subsection{Estudio cualitativo de los polifenoles del alpechín.}

De 20 a 40 microlitros de la solución concentrada de polifenoles en metanol se manchan en placas de celulosa de $20 \times 20 \mathrm{~cm}$ y se desarrolla en una dirección con ABA (fase superior de la mezcla agua- $n$ butanol-ácido acético $5: 4: 1$ ) y en otra con $\mathrm{AcOH} 2 \%$ (ácido acético-agua 2:98). Las placas, una vez secadas al aire, se observan a luz ultravioleta (254 y 366 $\mathrm{nm}$ ), antes y después de expuestas a vapores de amoníaco. El revelado se completa pulverizando con los siguientes reactivos (12):

a).-p-nitroanilina diazotada: Se mezclan en frío 1 $\mathrm{ml}$ de $\mathrm{p}$-nitroanilina $(0,5 \%$ en $\mathrm{HCl} 2 \mathrm{~N}), 10 \mathrm{ml}$ de nitrito sódico (5\% en agua) y $30 \mathrm{ml}$ de acetato sódico $(20 \%$ en agua). Después de pulverizar se rocía de nuevo con carbonato sódico ( $20 \%$ en agua). Los fenoles dan manchas de colores característicos.

b).-Reactivo de Arnow: Se mezclan $10 \mathrm{ml}$ de $\mathrm{HCl}$ $0,5 \mathrm{~N}$ con una solución de $1 \mathrm{~g}$ de nitrito sódico y 1 $\mathrm{g}$ de molibdato sódico en $10 \mathrm{ml}$ de agua. Después de pulverizar el cromatograma, se rocía nuevamente con $\mathrm{NaOH} 0,5 \mathrm{~N}$. Los orto-difenoles dan manchas rojas o anaranjadas.

\subsection{Medida de la Demanda Química de Oxíge-} no (DQO).

El método elegido para su determinación ha sido el del dicromato (flujo cerrado) (13). La muestra se somete a una oxidación química en caliente $\left(150^{\circ} \mathrm{C}\right)$ por adición de un exceso de oxidante (dicromato potásico) en medio de ácido sulfúrico. Tras un periodo de digestión, el exceso de dicromato que no ha reaccionado se valora frente a sulfato ferroso amónico. Por diferencia se determina la cantidad de dicromato consumida en la oxidación química de la muestra.

Si se desconoce el rango en que se encuentra la DQO de la muestra que se analiza, se preparan distintas diluciones de la misma con agua destilada.

Un volumen de $5 \mathrm{ml}$ de cada una de las diluciones y un blanco con agua destilada, con el mismo volumen, se colocan en los tubos de digestión. Se añaden, por tubo, $3 \mathrm{ml}$ de la solución de dicromato $(0,0167 \mathrm{M})$ y $7 \mathrm{ml}$ de la solución $\mathrm{Ag}_{2} \mathrm{SO}_{4}-\mathrm{H}_{2} \mathrm{SO}_{4}(5,5$ $\mathrm{g}$ de $\mathrm{Ag}_{2} \mathrm{SO}_{4} / \mathrm{kg}$ de $\mathrm{H}_{2} \mathrm{SO}_{4}$ ). Se cierran los tubos y se colocan en la placa calefactora. Se someten a digestión durante dos horas a $150^{ \pm 2} 0^{\circ} \mathrm{C}$. Pasado este tiempo, se dejan enfriar hasta temperatura ambiente. Se añaden unas gotas de ferroína $(1,485 \mathrm{~g}$ de 1,10-fenantrolina mononohidratada y $0,695 \mathrm{~g}$ de $\mathrm{FeSO}_{4} \cdot 7 \mathrm{H}_{2} \mathrm{O}$ en agua destilada y llevado a $100 \mathrm{ml}$ ) y se valoran frente a la solución de sulfato ferroso-amónico $0,1 \mathrm{M}$ $\left(39,2 \mathrm{~g}\right.$ de $\mathrm{Fe}\left[\mathrm{NH}_{4}\right]_{2}\left[\mathrm{SO}_{4}\right]_{2} \cdot 6 \mathrm{H}_{2} \mathrm{O}$ y $20 \mathrm{ml} \mathrm{de} \mathrm{H}_{2} \mathrm{SO}_{4}$ concentrado y llevado a 1 I con agua) hasta el viraje del indicador.

\subsection{Sustancias de referencia.}

Como patrones se han utilizado las siguientes sustancias puras de las firmas Fluka o Merck: ácidos cafeico, p-cumárico, protocatéquico y vaníllico, tirosol, apigenina, luteolina y quercetina. El hidroxitirosol se ha obtenido por reducción del ácido 3,4-dihidroxifenil-acético con hidruro de aluminio y litio. La oleuropeína, la 1-cafeil-glucosa y el monoglucósido del tirosol se obtuvieron a partir de pulpa de aceitunas por cromatografía preparativa. (8).

\subsection{Biodegradación de los fenoles del alpe-} chín.

Se ha llevado a cabo en dos fases (10). En primer lugar se somete el alpechín a un tratamiento aerobio con microorganismos específicos durante 5 días, al final de los cuales han disminuido drásticamente los polifenoles totales, orto-difenoles, meta-difenoles y la DQO. Posteriormente, este alpechín residual, una vez separada la biomasa por centrifugación, se somete a una biometanización anaerobia utilizando un reactor discontinuo de mezcla completa que contiene Sepiolita (Pansil) como soporte para la inmovilización de las bacterias responsables del proceso. 


\section{RESULTADOS EXPERIMENTALES}

En la Tabla I figuran los valores de los fenoles totales, los orto- y meta-difenoles y la DQO encontrados para el alpechín sin tratar y después de los tratamientos aerobio $y$ anaerobio.

En la Tabla II se muestran las estructuras y las reacciones coloreadas de los fenoles encontrados en el estudio cualitativo de los mismos.

La figura 1 corresponde a los cromatogramas en capa fina de celulosa, revelados con p-nitroanilina y molibdato sódico, respectivamente. La figura 2 es la correspondiente al alpechín tratado por vía aerobia y la figura 3 al tratado posteriormente por vía anaerobia.

Los números de las manchas se corresponden con los de los compuestos de la Tabla II.

Tabla I

Contenido en DQO ( $\mathrm{mg}$ de $\mathrm{O}_{2} / \mathrm{l}$ ), fenoles totales (ppm de ácido cafeico), orto-difenoles (ppm de ácido cafeico), metadifenoles (ppm de resorcina) y leucocianidinas (ppm de cloruro de cianidina) de los distintos extractos de alpechín.

\begin{tabular}{lccc} 
& $\begin{array}{l}\text { Alpechín } \\
\text { sin tratar }\end{array}$ & $\begin{array}{l}\text { Trataniento } \\
\text { aerobio }\end{array}$ & $\begin{array}{l}\text { Tratamiento } \\
\text { anaerobio }\end{array}$ \\
\hline DQO & 50.000 & 22.000 & 4.000 \\
Fenoles totales & 300 & 103 & 0,4 \\
Orto-difenoles & 23 & 3,8 & 0,3 \\
Meta-difenoles & 10,5 & 1,8 & - \\
Leucocianidinas & - & - & -
\end{tabular}

Tabla II

Estructura y reacciones coloreadas de los fenoles del alpechín.

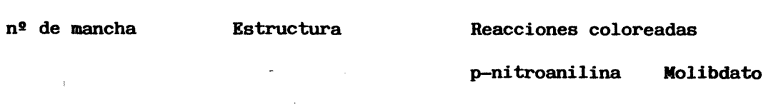

\begin{tabular}{rlll}
\hline 1 & Apigenina & amarilla & - \\
2 & Luteolina & $\begin{array}{l}\text { amarilla } \\
\text { amarilla }\end{array}$ & roja \\
3 & Quercetina & parda & roja \\
4 & Ac. trans-cafeico & parda & roja \\
4 & Ac. cis-cafeico & azul & - \\
6 & Ac. p-cumárico & magenta & - \\
6 & Ac. protocatéquico & magenta & - \\
8 & Ac. vaníllico & azul morada & roja \\
8 & Hidroxitirosol & morada & - \\
9 & Tirosol & parda rojiza & roja \\
10 & 0leuropeína & parda & roja \\
11 & 1-cafeil-glucosa & magenta & - \\
12 & moncglucósido de 9 & &
\end{tabular}

\section{DISCUSION DE LOS RESULTADOS.}

La cantidad de polifenoles presentes en un alpechín depende en gran medida del procedimiento seguido en la obtención del aceite. Los estudiados en este trabajo procedian de aceitunas procesadas en sistema continuo, en el que, para facilitar la centrifugación, se añade a la pasta de aceitunas una cantidad de agua que, lógicamente va al alpechín, dis-
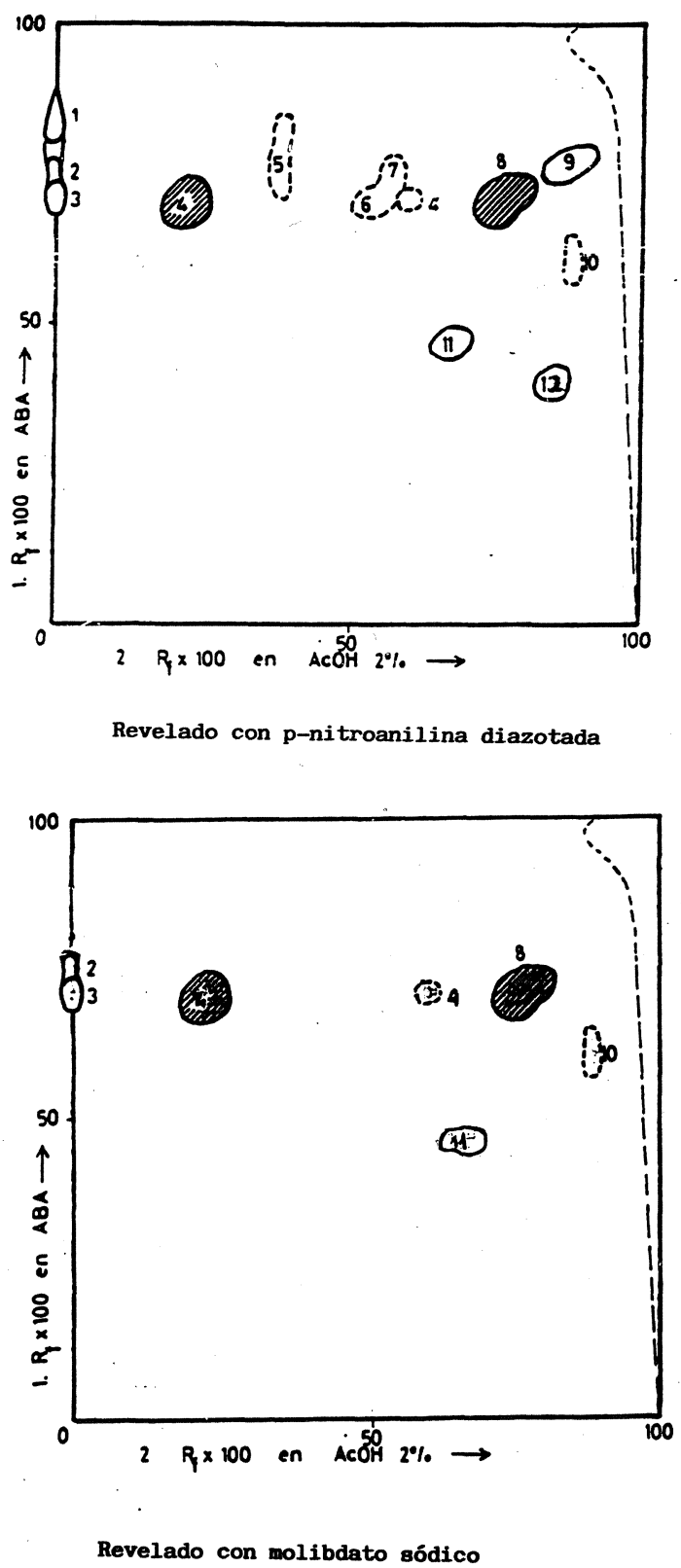

Figura 1

Fenoles de alpechín antes de los tratamientos. 
minuyendo la concentración de éste. En nuestro caso es del orden de 300 ppm. Esta cantidad de polifenoles, que unida a otras sustancias orgánicas produce una DQO del orden de $50.000 \mathrm{mg} /$ litro, produce una inhibición de las bacterias metanogénicas, como hemos visto en otro trabajo (7).

Los orto-difenoles suponen un porcentaje mucho menor que el existente en la pulpa de aceitunas, donde este grupo de compuestos es el mayoritario, alcanzando en muchos casos el $90 \%$ del total de polifenoles. En el alpechín este porcentaje se reduce

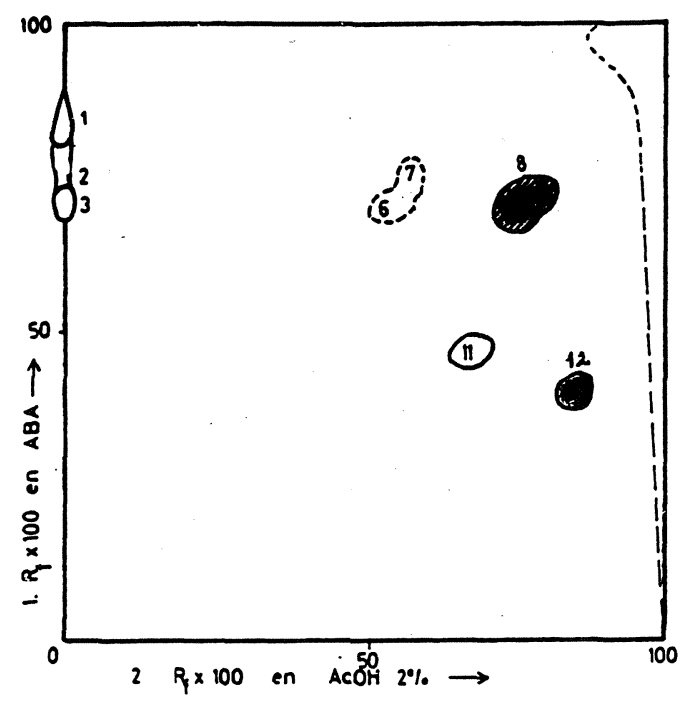

Revelado con p-nitroanilina diazotada

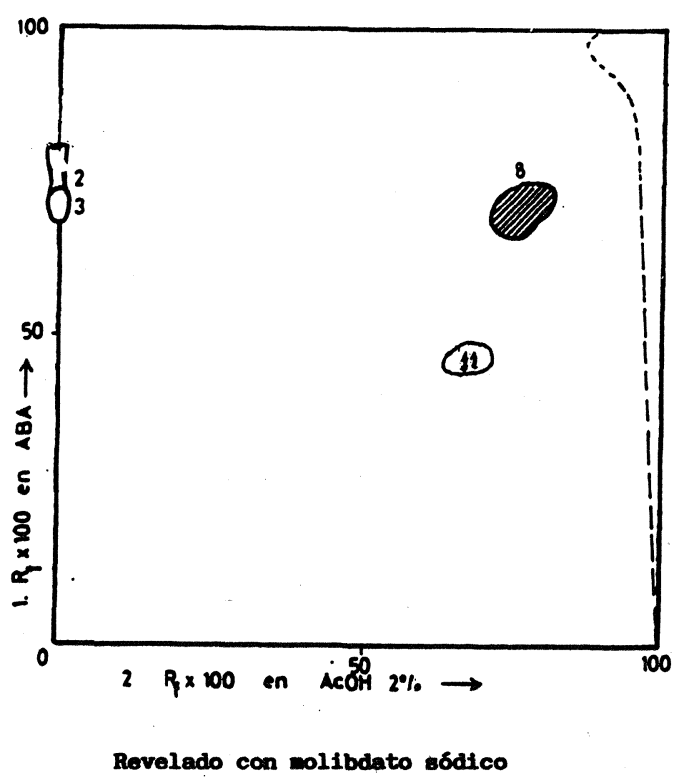

Figura 2

Fenoles del alpechín después del pretratamiento aerobio. muchísimo debido a las oxidaciones que tienen lugar en el proceso de extracción del aceite. Otro grupo de fenoles, los meta-difenoles, está también en proporciones pequeñas. La cantidad encontrada puede atribuirse a los flavonoides, de los que hemos encontrado un flavonol, la quercetina, y dos flavonas, la apigenina y la luteolina. También hemos investigado, con resultados negativos en todos los casos, la presencia de leucocianidinas. Estos resultados indican que las catequinas y taninos condensados no suponen, prácticamente, ninguna contribución a los polifenoles del alpechín.
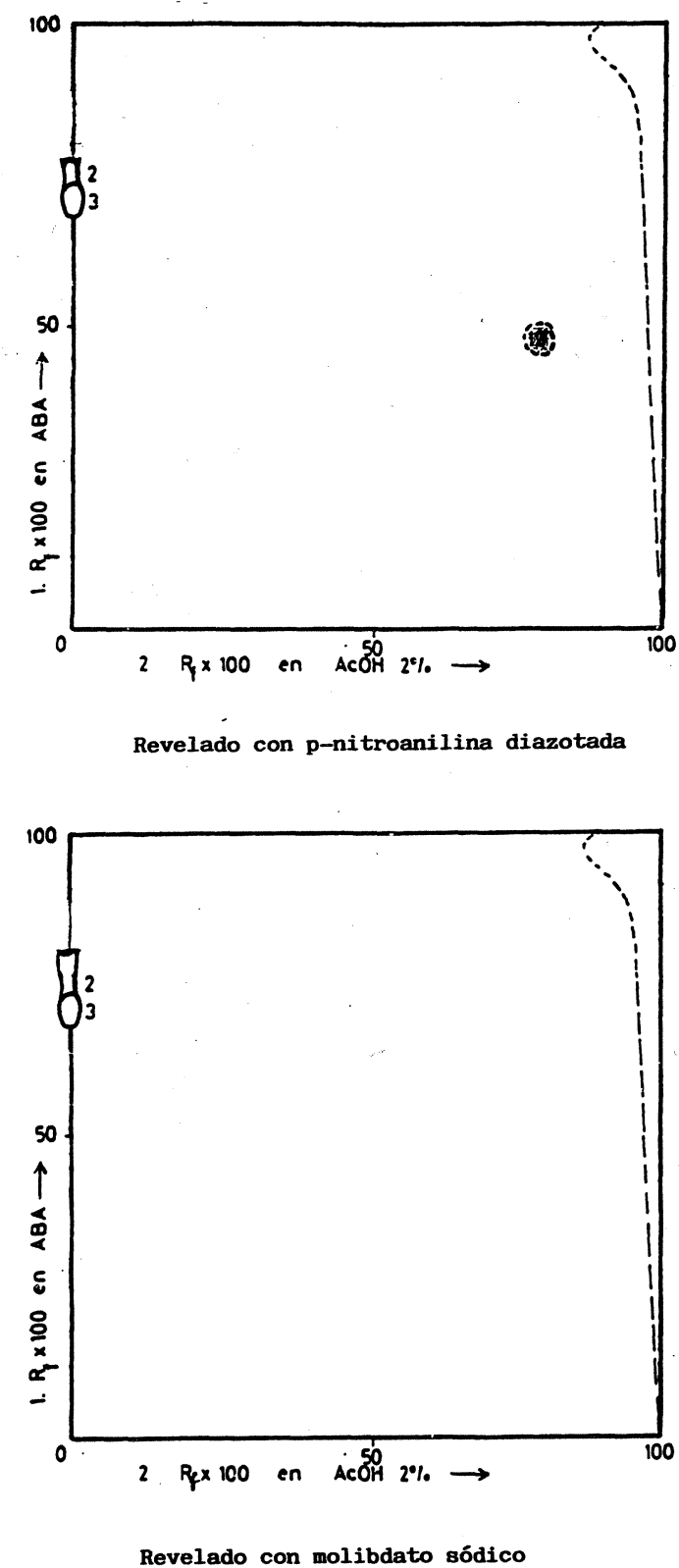

Figura 3

Fenoles del alpechín después del tratamiento anaerobio 
La mayor parte de los compuestos fenólicos del alpechín son, por lo tanto, sustancias con un solo grupo fenólico, situado por lo general en el carbono 4 del anillo bencénico (Figura 1).

Después del tratamiento aerobio, como se indica en la Tabla I y en la figura 2, ha disminuido en gran medida el valor de los distintos tipos de fenoles, habiendo desaparecido completamente, o por debajo del límite de detección, algunos de ellos (trans- y ciscafeico, p-cumárico, tirosol y oleuropeína). La DQO se redujo a menos de la mitad $\left(22.000 \mathrm{mgO}_{2} / \mathrm{l}\right)$.

El tratamiento anaerobio final transcurre en 4-5 días. No tuvo lugar ningún tipo de inhibición, presentando constantes de velocidad 5 veces más altas que en el alpechín sin biotratar. La DQO se redujo a 4.000 $\mathrm{mgO}_{2} / \mathrm{l}$ y se apreció una desaparición prácticamente total de los compuestos fenólicos inicialmente presentes en el alpechín (Tabla I y figura 3).

\section{CONCLUSIONES}

1.- Un tratamiento aerobio del alpechín con microorganismos específicos hace disminuir en gran medida la cantidad de polifenoles responsables de la inhibición de las bacterias metanogénicas.

2.- Un tratamiento anaerobio posterior hace desaparecer casi completamente estos compuestos fenólicos, siendo las constantes de velocidad de dicho proceso anaerobio 5 veces más elevadas que en el alpechín sin tratamiento previo.

3.- La eficiencia de eliminación de la DQO del proceso completo es del $92 \%$.

4.- La biodegradación final de fenoles totales y orto-difenoles es del 99,9\% y $98,2 \%$, respectivamente.

\section{AGRADECIMIENTOS}

A D. a Carmen Sánchez González, D. a Antonia Escobar de la Torre y D. Miguel Caro Sánchez por su eficaz ayuda en la realización de este trabajo.

\section{BIBLIOGRAFIA}

1. Field, J. A., Lettinga, G. y Geurts, M.- "The methanogenic toxicity and anaerobic degradability of potato starch wastewater phenolic amino acis".- Biological Wates 21 (1987) 37-54.

2. Fedorak, P. M. y Hrudey, S. E.- "Inhibition of anaerobic degradation of phenolics and methanogenesis by coal coking wastewater".- Wat. Sci. Techn, 19 (1987) 219-228.

3. Benjamin, M. M., Wood, S. L. y Ferguson, J. F.- "Anaerobic toxicity and biodegradability of pulp mill waste constituents".Water Res. 18 (1984) 601-607.

4. De Caro, M. y Ligore, M.G.- "Attivita antibiotica di un estracto desunto delle acque di vegetezione delle oliven".- Riv. Ist. Super. Sanita 22 (1959) 223-245

5. Balice, C., Carrieri, C., Liberti, L., Passino, R y Satori, M."Trattamento biologico abbinato aerobico delle acque di vegetazione di frantoio".- Ingegneria Sanitaria 2 (1985) 69-78.

6. Sorlini, C., Andreoni, V., Ferrari, A. y Ranall., G.- "The influence of some phenolic acids present in oil-mill waters on microbic groups for the methanogenesis".- International Symposium on olive by products valoration, Sevilla (1986) 81-88.

7. Rodríguez, M., Pérez, J., Ramos Cormazana, A y Martínez, J.- "Effect of extracts obtained from olive wastewater on Bacillus megaterium ATCC $33085^{n}$.- J. Appl. Bacteriol 64 (1988) 219-226.

8. Vázquez Roncero, A., Maestro Durán, R. y Graciani Constante, E.- "Componentes fenólicos de la aceituna I. Polifenoles de la pulpan.- Grasas y Aceites 25 (1974) 269-279.

9. Vázquez Roncero, A., Maestro Durán, R. y Graciani Constante, E.- "Polifenoles de la aceituna II. Polifenoles del alpechín".- Grasas y Aceites 25 (1974) 341-345.

10. Borja Padilla, R., Martín Martín, A., Maestro Durán, R, Alba Mendoza, J. y Fiestas Ros de Ursinos, J. A.- "Cinética del proceso de depuración anaerobia de alpechín previamente tratado vía aerobian.- Grasas y Aceites 42 (1991) 194-201.

11. Vázquez Roncero, A., Maestro Durán, R. y Graciani Constante, E.-"Cambios en los polifenoles de la aceituna durante la maduración".- Grasas y Aceites 22 (1971) 366-370.

12. Stalh, E.- "Thin Layer Chromatography".- 2. Ed.- Springer Verlag, Berlín, 1967.

13. American Public Health Association.- "Standard Methods for the examination of water and wastewater".- 16 Ed.Washington, 1985.

(Recibido: Octubre 1990) 